\title{
Ultrasound imaging of the fetal optic nerve from a different plane
}

\author{
Erzat Toprak $^{1}$ (D), Mehmet Murat Işııalan² \\ ${ }^{1}$ Perinatology Clinic, Kayseri City Hospital, Kayseri, Turkey \\ ${ }^{2}$ Department of Perinatology, Faculty of Medicine, Necmettin Erbakan University, Konya, Turkey
}

\begin{abstract}
Objective: In this study, we aimed to visualize the fetal optic nerve and its sheath in a lateral oblique plane by ultrasound.

Methods: This cross-sectional prospective study was conducted at 20-22 weeks of gestation on healthy pregnant women who applied to our perinatology clinic for anomaly screening. Optic nerve sheath diameter (ONSD) measurements were taken from the lateral orbital and the retroorbital planes twice by the same sonographer. Ultrasound durations were recorded. Intraobserver variability was calculated for both techniques. The Bland-Altman analysis was performed for the lateral orbital technique.

Results: A total of 45 pregnant women were evaluated in the study. The intraclass correlation coefficient value of the lateral orbital technique was $0.722(\mathrm{p}<0.001)$, suggesting that the ONSD was measured similarly by the same observer. The ONSD mean measured by the lateral orbital (LO) technique was higher than the ONSD mean measured by the retroorbital $(\mathrm{RO})$ technique $(2.10 \pm 0.13$ vs $1.21 \pm 0.13 \mathrm{~mm}$, $\mathrm{p}<0.001)$. The ONSD measurement with the LO technique was determined to be more time-effective than the RO technique $(129.6 \pm 31.3$ vs $228.2 \pm 32.7 \mathrm{sec}, \mathrm{p}<0.001)$.

Conclusion: It is demonstrated that by using the lateral orbital technique, the optic nerve and its sheath can be visualized separately without the shadowing artifact of the lens. This technique also takes less time than the $\mathrm{RO}$ technique. There is a need for more extensive research on this subject with magnetic resonance imaging (MRI) confirmation.
\end{abstract}

Keywords: Fetal optic nerve, septo-optic dysplasia, optic nerve hypoplasia, optic nerve sheath diameter.

\section{Introduction}

The optic nerve is an extension of the central nervous system and is covered with a sheath consisting of three meninges and some cerebrospinal fluid. The optic nerve and its sheath together are called the optic nerve complex $^{[1]}$ (Fig. 1).

\section{Özet: Fetal optik sinirin farklı bir plandan ultrason görüntülemesi}

Amaç: Bu çalışmada, fetal optik siniri ve kılıfinı ultrason ile lateral oblik bir planda görüntülemeyi amaçladık.

Yöntem: Bu kesitsel prospektif çalışma, gebeliğin 20-22. haftasında anomali taraması için perinatoloji kliniğimize başvuran sağlıklı gebelerle gerçekleştirildi. Optik sinir kılıfı çapı (OSKÇ) ölçümleri, aynı sonografi uzmanı tarafindan lateral orbital ve retro-orbital planlarda iki kere yapıldı. Ultrason süreleri kaydedildi. Gözlemci içi değişkenliği her iki teknik için de hesaplandı. Lateral orbital teknik için Bland-Altman analizi gerçekleştirildi.

Bulgular: Çalışmada toplam 45 gebe değerlendirildi. Lateral orbital tekniğin sınıf içi korelasyon katsayısı değeri 0.722 idi $(\mathrm{p}<0.001)$, bu da OSKÇ'nin aynı gözlemci tarafindan benzer şekilde ölçüldüğünü göstermektedir. Lateral orbital (LO) teknikle ölçülen OSKÇ ortalaması, retro-orbital (RO) teknikle ölçülen OSKÇ ortalamasından yüksekti $(2.10 \pm 0.13$ mm'ye karşı $1.21 \pm 0.13$ $\mathrm{mm}, \mathrm{p}<0.001)$. LO teknikle OSKÇ ölçümünün, RO tekniğe kıyasla zaman açısından daha etkin olduğu belirlenmiştir (129.6 \pm 31.3 saniyeye karşı $228.2 \pm 32.7$ saniye, $\mathrm{p}<0.001$ ).

Sonuç: Lateral orbital tekniği kullanarak, lensin gölge artefaktı olmaksızın optik sinirin ve kılıfının ayrı ayrı görüntülenebileceği sonucuna vardık. Bu teknik ayrıca, RO teknikten daha kısa sürmektedir. Manyetik rezonans görüntüleme (MRG) doğrulaması ile bu konuda daha kapsamlı araştırmaya ihtiyaç duyulmaktadır.

Anahtar sözcükler: Fetal optik sinir, septo-optik displazi, optik sinir hipoplazisi, optik sinir kılıfi çapı.

Correspondence: Mehmet Murat Işskalan, MD. Department of Perinatology, Faculty of Medicine, Necmettin Erbakan University, Konya, Turkey. e-mail: muratisikalan@gmail.com / Received: December 3, 2020; Accepted: December 24, 2020

How to cite this article: Toprak E, Işıkalan MM. Ultrasound imaging of the fetal optic nerve from a different plane. Perinatal Journal 2021;29(1):1-7. doi:10.2399/prn.21.0291001 
pathologies such as the absence of cavum septum pellucidum (CSP) and intracranial space-occupying lesions. ${ }^{[4-6]}$ Generally, retroorbital approaches that visualize the optic nerve from anterior to posterior have been used for visualization of the optic nerve. ${ }^{[7]}$

Currently, ultrasound resolution is thought to be insufficient to distinguish the optic nerve from the surrounding nerve sheath. Therefore, the optic nerve and its sheath have always been evaluated together in fetal ultrasonography studies performed. ${ }^{[7-9]}$ According to our current information, no fetal ultrasonography study has been conducted to date in order to distinguish the optic nerve from its sheath. In this study, we aimed to visualize the fetal optic nerve and its sheath in a different plane that enables it to be distinguished ultrasonographically.

\section{Methods}

This cross-sectional prospective study was conducted between 20 and 22 weeks gestation on healthy pregnant women who applied to our perinatology clinic for anomaly screening between January and May 2020. The sample size was calculated with the $G^{*}$ Power 3.1 statistical analysis program (Erdfelder, Faul and Buchner, Düsseldorf, Germany). ${ }^{[10]}$ The $\alpha$ error probability, effect size and power of the study were $0.05,0.5$ and 0.95 respectively. The total required sample size was determined as 45 .

This study was approved by the local institutional Ethics Committee of the hospital. An informed consent form was read to all pregnant women participating in the study and their signed approvals were obtained. Healthy singleton pregnancies were included in the study. Exclusion criteria included women with chronic disease, fetal anomalies, multifetal pregnancies, fetal growth restriction or suspected gestational age. Demographic information and the obstetric history of all the participants were recorded. The gestational age was calculated according to the last menstrual period and confirmed based on the result of a first trimester ultrasound.

A Samsung HS70A (Hampshire, UK) ultrasound machine equipped with a 1-7 Mhz convex abdominal transducer was used for all ultrasound evaluations. All measurements were performed by a single sonographer (E.T) who is a maternal-fetal medicine specialist with 15 years of fetal neurosonography experience. All ultrasound examinations were performed transabdominally. First, anomaly screening was performed for all patients. It was determined that both eyeballs were normal and

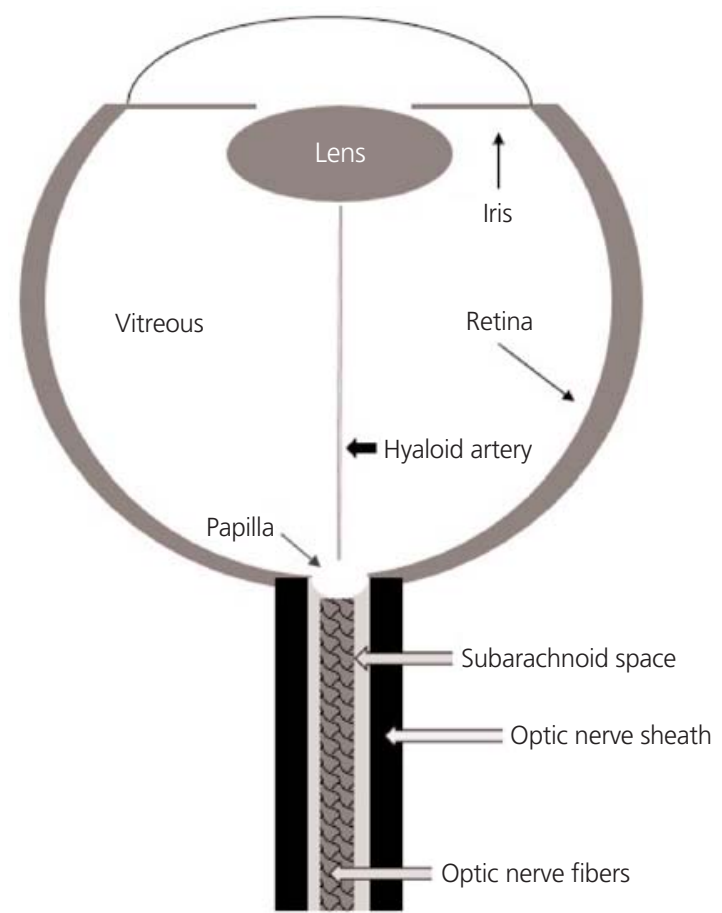

Fig. 1. Schematic view of the eyeball and the optic nerve complex.

there was no cranial anomaly. Placenta location was determined and recorded as fundal, lateral, anterior or posterior according to the area covered by more than fifty percent of the placenta. Then, optic nerve measurements were performed unilaterally. Measurements were performed after magnification until one orbit remained in the imaging area. All measurements were performed by using the magnifiers. The cine-loop function was used because the optic nerve also moves due to eye movements. Images of all optic nerve measurements were recorded and archived.

According to our experience, even for a sonographer experienced in prenatal ultrasonography, the learning curve for the LO technique takes about 2 months. ONSD was measured twice in the lateral orbital (LO) and retro-orbital (RO) planes. In the preliminary evaluation of 20 patients before the study, it was found that there was no difference between the measurements away from the probe and close to the probe. Therefore, due to time and ergonomic reasons, the optic nerve away from the probe was measured for the LO technique (Fig. 2). For the RO technique, optic nerve close to probe was measured. 

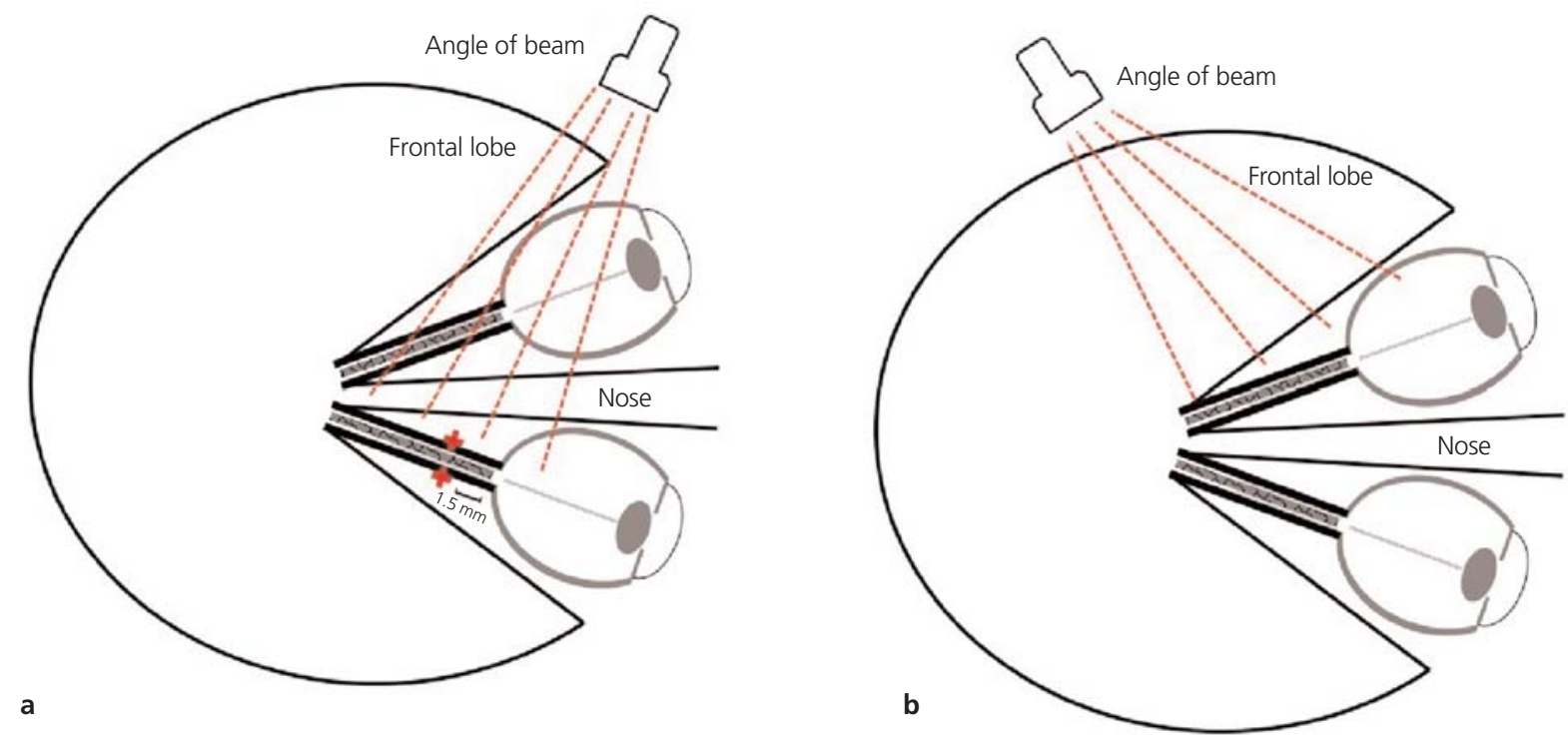

Fig. 2. (a) Drawing of optic nerve and angle of the beam away from the ultrasound probe. (b) Drawing of optic nerve and angle of the beam close to the ultrasound probe.

To visualize the optic nerve in the LO plane, the orbit was viewed laterally relative to the fetal position. First the lens and then the hyaloid artery was visualized. In the next step, taking into account the course of the optic nerve complex (lateral to medial and anterior to posterior), the probe was angled from the eyeball to the optical foramen, from the anterior to the posterior and from the lateral to the medial. The ultrasound probe insonation angle was adjusted to 90 degrees to the optic nerve complex. ONSD was measured from the $1.5 \mathrm{~mm}$ posterior of the papilla by including the outer borders (on to on) (Fig. 3).

Measurements with the RO technique were performed as previously described in the study of Haratz et al. ${ }^{[7]}$ In this technique, ONSD was measured when the fetal eye was on the axial plane at lens level and face positioned towards the probe or at a 45 degree angle from the midline (Fig. 4). All measurement durations were recorded using the monitor clock. For each technique, the arithmetic mean of the two measurement durations was recorded. The study continued until the required number of samples was completed.

All the data collected for statistical analysis were analyzed using the Statistical Package for the Social Sciences (SPSS), version 23, (SPSS Inc., Chicago, IL, USA). Descriptive characteristics were calculated for the rele- vant variables. Continuous and categorical variables were given as median, mean \pm standard deviation or number (\%). The normal distributions of the data were evaluated using the Kolmogorov-Smirnov test. The paired-samples t-test, the intraclass correlation coefficient and the Bland-Altman plots were used to evaluate consistency between the ONSD measurements. ${ }^{[1]]}$

\section{Results}

A total of 45 healthy pregnant women at 20-22 weeks of gestation were included in this study. The mean age of the participants was $26.7 \pm 5.2$ years. Other demographic data are shown in Table 1.

The ONSD measurement was performed in all 45 pregnant women using the LO technique. The optic tract was intact in all of the pregnant women. For both measurements using this technique, the paired-samples t-test was used to determine intraobserver variability and no significant difference was found between the measurements $(\mathrm{p}=0.310)$. The intraobserver reliability was assessed using a two-way random, absolute agreement, average measures intraclass correlation coefficient (ICC) to assess the degree of reliability between two different measurements of the same sonographer when measuring ONSD. The ICC value was 0.722 $(95 \% \mathrm{CI}=0.49-0.84, \mathrm{p}<0.001)$ and suggesting that 

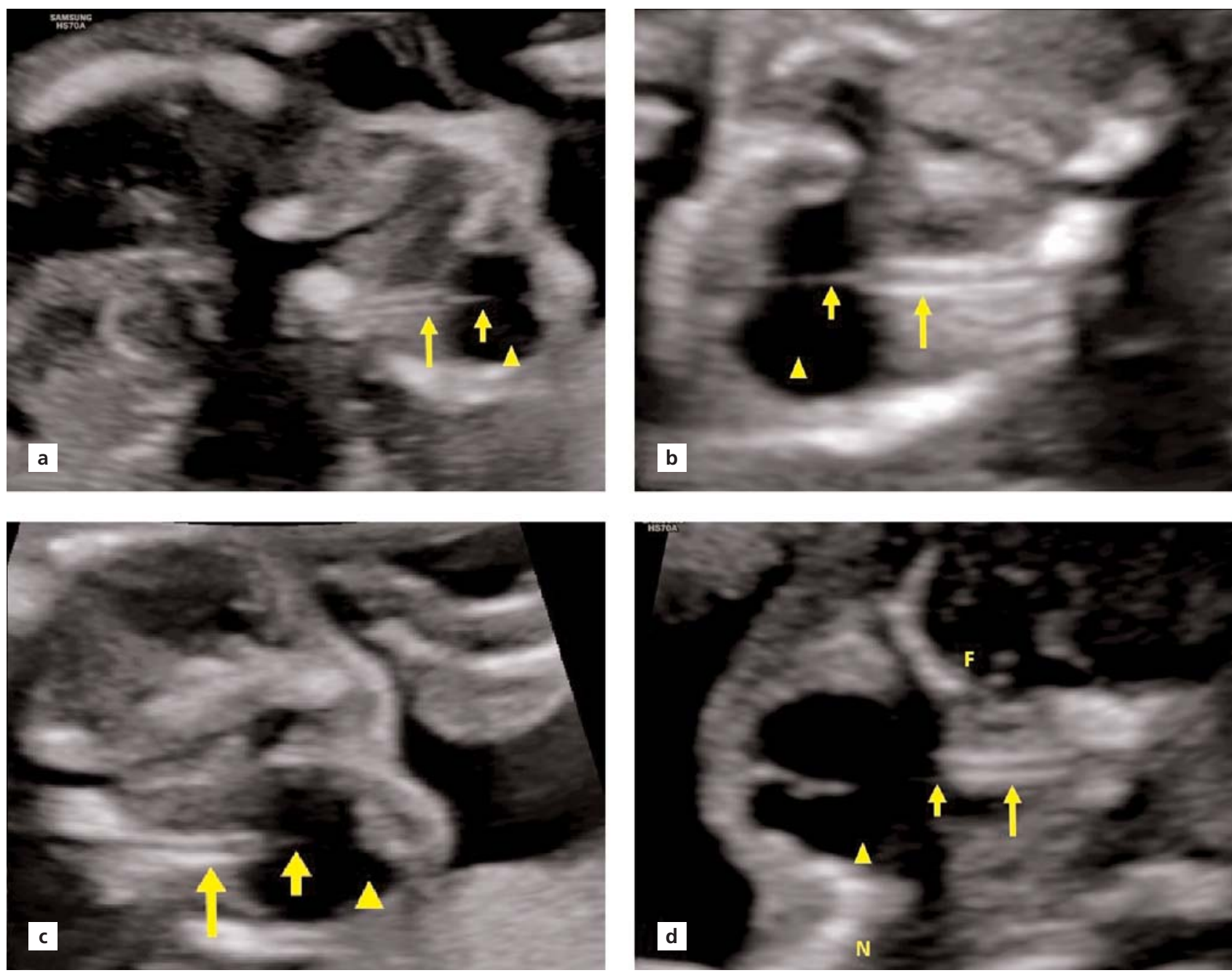

Fig. 3. Lateral orbital view of the eyeball. These images show the optic nerve and its sheath (long arrow), the hyaloid artery (short arrow) and eyeball (arrowhead). (a and $\mathbf{c}$ ) The the small appearance of the optic nerve away from the ultrasound probe in different patients. There are two orbits on the screen. (b) Optimal measurement of the optic nerve away from the ultrasound probe. There is only one orbit on the screen. (d) Optimal view of the optic nerve close to the ultrasound probe. There is only one orbit on the screen. $\mathrm{F}$ : frontal lobe; $\mathrm{N}$ : nose.

ONSD was measured similarly by the same observer. The mean of differences was $0.024 \mathrm{~mm}$ (95\% limits of agreement $-0.28+0.33)$ and the standard deviation was $\pm 0.15 \mathrm{~mm}$ in the Bland-Altman plot (Fig. 5).

Optic nerve measurement was performed in 44 of 45 patients with the RO technique. Measurement could not be performed in one patient because the fetus was the dorsoanterior position and the patient did not agree to transvaginal ultrasound. For both measurements using the RO technique, the paired-samples t-test was used to determine intraobserver variability and no significant difference was found between the measurements $(\mathrm{p}=0.118)$. The ICC value was 0.677 (95\% CI $=0.41-0.82, \mathrm{p}<0.001$ ), suggesting that the ONSD was measured similarly by the same observer.

The mean of the ONSD measurements using the LO technique was $2.10 \pm 0.13 \mathrm{~mm}$ and the mean of the ONSD measurements with the RO technique was $1.21 \pm 0.13 \mathrm{~mm}$ (Table 2). A significant difference was observed between the ONSD values resulting from these two measurement techniques (ICC $=0.015,95 \%$ $\mathrm{CI}=0.20-0.76, \mathrm{p}<0.001)$. The mean duration of the 


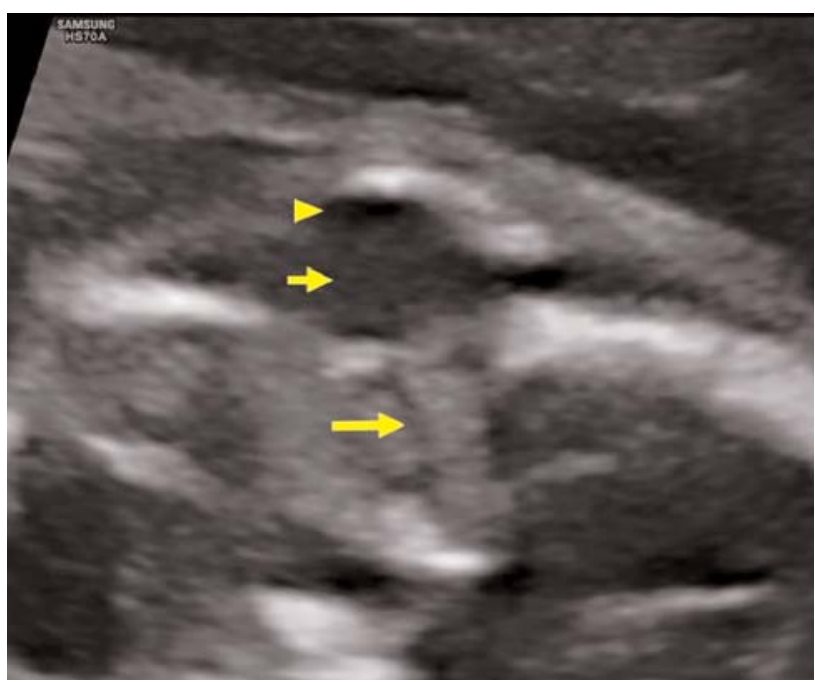

Fig. 4. Retro-orbital view showing the optic nerve complex (long arrow), eyeball (short arrow) and lens (arrowhead). The lens is viewed as a hypoechoic area.

ONSD measurement was $129.6 \pm 31.3 \mathrm{sec}$ with the LO technique and $228.2 \pm 32.7 \mathrm{sec}$ with the RO technique $(\mathrm{p}<0.001)$ (Table 2).

\section{Discussion}

In this study, we have provided the ultrasonographic imaging of the fetal optic nerve in the lateral orbital plane. With this technique, we aimed to demonstrate that the visualization of the optic nerve is easily applicable, inexpensive, reproducible, time-effective and that the optic nerve and its sheath can be viewed clearly without the need for high resolution ultrasonography devices.

Although fetal ultrasound evaluation of the optic nerve was first performed in the 80 s, there have been only a few studies performed with $2 \mathrm{D}$ ultrasound since. These studies were performed on retro-orbital axial planes. ${ }^{[9]}$ In children and adults, besides axial planes, coronal approaches have been used to display ONSD, but both methods have had limitations as to technical and potential imaging artifacts. In this study, we tried to display the optic nerve complex, which is difficult in the fetus, from the lateral orbital angle. We have determined that this technique is time effective. To the best of our knowledge, there is no data in the literature regarding how long this measurement lasts.

In the retro-orbital approach to ONSD measurement, ultrasound waves transmit from anterior to poste-

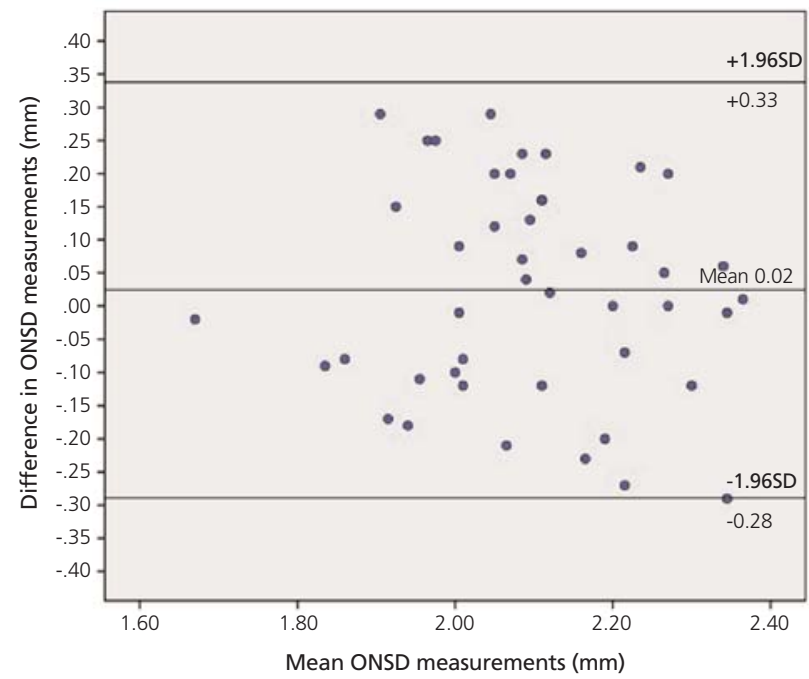

Fig. 5. Bland-Altman plot showing intraobserver variability of the optic nerve sheath diameter (ONSD) values measured using the lateral orbital technique.

Table 1. Descriptive characteristics of the study population.

\begin{tabular}{|c|c|}
\hline Parameter & Value \\
\hline Age (years)* & $26.7 \pm 5.2$ \\
\hline Gravidity ${ }^{\dagger}$ & $2(1.6)$ \\
\hline Parity $^{\dagger}$ & $1(0.4)$ \\
\hline Gestational age (week)* & $21.4 \pm 0.7$ \\
\hline Number of abortions ${ }^{\dagger}$ & $0(0.2)$ \\
\hline BMI $\left(\mathrm{kg} / \mathrm{m}^{2}\right)^{\star}$ & $26.9 \pm 5.0$ \\
\hline \multicolumn{2}{|l|}{ Placental location¥ } \\
\hline Anterior & $23(51.1)$ \\
\hline Fundus & $15(33.3)$ \\
\hline Posterior & $7(15.6)$ \\
\hline \multicolumn{2}{|l|}{ Fetal presentation ${ }^{\ddagger}$} \\
\hline Vertex & $22(48.9)$ \\
\hline Breech & $18(40)$ \\
\hline Other & $5(11.1)$ \\
\hline
\end{tabular}

Data are presented as mean $\pm S D^{*}$, median (range $)^{\dagger}$ or $\mathrm{n}(\%)^{\ddagger}$ as appropriate. BMI: body mass index.

Table 2. Mean ONSD, duration and ICC values of the lateral orbital and the retro-orbital techniques.

\begin{tabular}{lccc} 
& LO technique & RO technique & p-value \\
ONSD $(\mathrm{mm})$ & $2.10 \pm 0.13$ & $1.21 \pm 0.13$ & $\mathrm{p}<0.001^{*}$ \\
Duration $(\mathrm{sec})$ & $129.6 \pm 31.3$ & $228.2 \pm 32.7$ & $\mathrm{p}<0.001^{*}$ \\
ICC & 0.722 & 0.677 & - \\
\hline
\end{tabular}

*The paired-samples t-test was performed. ICC: intraclass correlation coefficient; LO: lateral orbital; ONSD: optic nerve sheath diameter; RO: retro-orbital. 
rior and the optic nerve complex is displayed behind the eyeball. When the ultrasound beam encounters a focal material that weakens the sound, the strength of the beam away from this structure will be weaker than the surrounding area (attenuation artifact or shadowing). ${ }^{[12]}$ Therefore, retro-orbital techniques actually measure the shadow of the optic disc, not the axial nerve sheath. In contrast to measuring a true anatomical structure, it can be expected that it will be difficult to accurately measure the shadow artifact. This may be a major disadvantage, especially in the differential diagnosis of conditions such as optic nerve hypoplasia. However, while ONSD is measured in the lateral orbital plane as we defined in this study, ultrasound waves do not encounter the dense structure of the lens.

Another technique used by ophthalmologists for ONSD measurement is coronal imaging. This technique is mostly used to prevent the lens from causing shadowing artifacts. ${ }^{[13]}$ In a study where Blehar et al. compared the axial and coronal planes in ONSD measurement in adults, coronal and axial (visual axis) measurements were found to be quite different from each other. ${ }^{[14]}$ To the best of our knowledge, there is no study on coronal technique in the evaluation of fetal optic nerve. In one study, it was revealed that even the distal part of the optic nerve sheath can be viewed with a high resolution 3.0 Tesla magnetic resonance imaging (MRI). The distal part (i.e. posterior) of the optic nerve is thinner and more difficult to measure. In the same study, it was shown that the optic nerve narrows from anterior to posterior. ${ }^{[15]}$ An imaging technique that can demonstrate this, other than MRI, has not yet been defined. However, it is possible to show that the optic nerve narrows towards the posterior in ultrasound measurements with the LO technique (Fig. 3).

Studies have shown that ONSD expands with increased intracranial pressure in children and adults. ${ }^{[16-18]}$ Haratz et al. also showed that fetal ONSD is wider in the presence of an intracranial mass that increases intracranial pressure in fetuses. ${ }^{[7]}$ In our study, the optic nerve sheath was measured from the $1.5 \mathrm{~mm}$ posterior of the papilla, showing compatibility with Haratz et al. Since the optic nerve tract can be easily monitored through the LO approach, standardization is easy, such as by axial measurement.

Haratz et al. published optic nerve percentiles in another study. ${ }^{[8]}$ Bault et al. also performed optic nerve measurements with 3D ultrasonography and published their percentiles. ${ }^{[19]}$ It is noteworthy that reference intervals determined in the study by Haratz et al. are smaller than values obtained by $3 \mathrm{D}$ ultrasound imaging by Bault et al. ${ }^{[7]}$ The results we found in our study are closer to the 3D measurements of Bault et al. Alonso et al. showed that optic chiasm can be fully visualized by fetal ultrasonography. ${ }^{[20]}$ In their study, Vinal et al. showed that it would be possible to evaluate fetal optic chiasm from the coronal plane with transvaginal ultrasound. ${ }^{[2]}$ However, optic nerve measurement was not defined in these studies.

Considering that optic nerve hypoplasia is the most common congenital optic disc pathology and is one of the major causes of blindness and may accompany other anomalies, the importance of optic nerve imaging is better understood. ${ }^{[2]}$ However, optic nerve measurement is not included in routine screening guidelines. ${ }^{[23]}$ Since the LO technique is easy and time-effective, it may be suggested that the optic nerve become a part of routine scans in the future.

This study is the first to describe the lateral orbital plane in optic nerve imaging. It is possible to evaluate the optic nerve and its sheath separately from this plane. However, this study has limitations. First, interobserver variability has not been evaluated and the sample size was relatively small. Secondly, measurements were performed only in fetuses in the 20-22 week period. The main deficiency of this study, and indeed all other studies related to fetal optic nerve measurement, is that MRI confirmation, which is the gold standard for OSND measurements, could not be performed.

\section{Conclusion}

In this study, we showed that by using the lateral orbital technique, the optic nerve and its sheath can be visualized separately without the shadowing artifact of the lens. This technique also takes less time than the $\mathrm{RO}$ technique. There is a need for more extensive research on this subject with MRI confirmation.

Funding: This work did not receive any specific grant from funding agencies in the public, commercial, or not-for-profit sectors.

Compliance with Ethical Standards: The authors stated that the standards regarding research and publication ethics, the Personal Data Protection Law and the copyright regulations applicable to intellectual and artistic works are complied with and there is no conflict of interest. 


\section{References}

1. Selhorst JB, Chen Y. The optic nerve. Semin Neurol 2009; 29:29-35. [PubMed] [CrossRef]

2. Pilu G, Tani G, Carletti A, Malaigia S, Ghi T, Rizzo N. Difficult early sonographic diagnosis of absence of the fetal septum pellucidum. Ultrasound Obstet Gynecol 2005;25: 70-2. [PubMed] [CrossRef]

3. Bault, JP. OC76: Prognostic value of fetal optic chiasm measurements in fetuses with septal agenesis. Ultrasound Obstet Gynecol 2007;30:390. [CrossRef]

4. Garcia-Filion P, Borchert M. Prenatal determinants of optic nerve hypoplasia: review of suggested correlates and future focus. Surv Ophthalmol 2013;58:610-9. [PubMed] [CrossRef]

5. Borchert M. Reappraisal of the optic nerve hypoplasia syndrome. J Neuroophthalmol 2012;32:58-67. [PubMed] [CrossRef]

6. Gala F. Magnetic resonance imaging of optic nerve. Indian J Radiol Imaging 2015;25:421-38. [PubMed] [CrossRef]

7. Haratz K, Vinals F, Lev D, Feit H, Ben-Sira L, Lerman-Sagie T, et al. Fetal optic nerve sheath measurement as a non-invasive tool for assessment of increased intracranial pressure. Ultrasound Obstet Gynecol 2011;38:646-51. [PubMed] [CrossRef]

8. Haratz KK, Melcer Y, Leibovitz Z, Feit H, Lerman-Sagie T, Lev D, et al. Ultrasound nomograms of the fetal optic nerve sheath diameter. Ultraschall Med 2019;40:476-80. [PubMed] [CrossRef]

9. Birnholz JC. Ultrasonic fetal ophthalmology. Early Hum Dev 1985;12:199-209. [PubMed] [CrossRef]

10. Faul F, Erdfelder E, Lang AG, Buchner A. G*Power 3: a flexible statistical power analysis program for the social, behavioral, and biomedical sciences. Behav Res Methods 2007;39:175-91. [PubMed] [CrossRef]

11. Bland JM, Altman DG. Statistical methods for assessing agreement between two methods of clinical measurement. Lancet 1986:1(8476):307-10. [PubMed] [CrossRef]

12. Feldman MK, Katyal S, Blackwood MS. US artifacts. Radiographics 2009;29:1179-89. [PubMed] [CrossRef]

13. Liu D, Kahn M. Measurement and relationship of subarachnoid pressure of the optic nerve to intracranial pressures in fresh cadavers. Am J Ophthalmol 1993;116:548-56. [PubMed] [CrossRef]

14. Blehar DJ, Gaspari RJ, Montoya A, Calderon R. Correlation of visual axis and coronal axis measurements of the optic nerve sheath diameter. J Ultrasound Med 2008;27:407-11. [PubMed] [CrossRef]

15. Weigel M, Lagrèze WA, Lazzaro A, Hennig J, Bley TA. Fast and quantitative high-resolution magnetic resonance imaging of the optic nerve at 3.0 Tesla. Invest Radiol 2006;41:83-6. [PubMed] [CrossRef]

16. Newman WD, Hollman AS, Dutton GN, Carachi R. Measurement of optic nerve sheath diameter by ultrasound: a means of detecting acute raised intracranial pressure in hydrocephalus. Br J Ophthalmol 2002;86:1109-13. [PubMed] [CrossRef]

17. Kimberly HH, Shah S, Marill K, Noble V. Correlation of optic nerve sheath diameter with direct measurement of intracranial pressure. Acad Emerg Med 2008;15:201-4. [PubMed] [CrossRef]

18. Geeraerts T, Launey Y, Martin L, Pottecher J, Vigué B, Duranteau J, et al. Ultrasonography of the optic nerve sheath may be useful for detecting raised intracranial pressure after severe brain injury. Intensive Care Med 2007;33:1704-11. [PubMed] [CrossRef]

19. Bault JP, Salomon LJ, Guibaud L, Achiron R. Role of threedimensional ultrasound measurement of the optic tract in fetuses with agenesis of the septum pellucidum. Ultrasound Obstet Gynecol 2011;37:570-5. [PubMed] [CrossRef]

20. Alonso I, Azumendi G, Romero M, Andérica JR, Herrero JR, Azumendi P, et al. Fetal optic chiasm: three steps for visualization and measurement on routine transabdominal ultrasound. Ultrasound Obstet Gynecol 2019;54:135-6. [PubMed] [CrossRef]

21. Viñals F, Ruiz P, Correa F, Gonçalves Pereira P. Twodimensional visualization and measurement of the fetal optic chiasm: improving counseling for antenatal diagnosis of agenesis of the septum pellucidum. Ultrasound Obstet Gynecol 2016;48:733-8. [PubMed] [CrossRef]

22. Mohney BG, Young RC, Diehl N. Incidence and associated endocrine and neurologic abnormalities of optic nerve hypoplasia. JAMA Ophthalmol 2013;131:898-902. [PubMed] [CrossRef]

23. Salomon LJ, Alfirevic Z, Berghella V, Bilardo C, HernandezAndrade E, Johnsen SL, et al.; ISUOG Clinical Standards Committee. Practice guidelines for performance of the routine mid-trimester fetal ultrasound scan. Ultrasound Obstet Gynecol 2011;37:116-26. [PubMed] [CrossRef]

This work is licensed under the Creative Commons Attribution-NonCommercial-NoDerivs 4.0 Unported (CC BY-NC-ND4.0) License. To view a copy of this license, visit http://creativecommons.org/licenses/by-nc-nd/4.0/ or send a letter to Creative Commons, PO Box 1866, Mountain View, CA 94042 , USA.

Publisher's Note: The content of this publication does not necessarily reflect the views or policies of the publisher, nor does any mention of trade names, commercial products, or organizations imply endorsement by the publisher. Scientific and legal responsibilities of published manuscript belong to their author(s). The publisher remains neutral with regard to jurisdictional claims in published maps and institutional affiliations. 